\title{
Natalie Petiteau, Les Français et l'Empire (1799-1815)
}

\author{
Cyril Triolaire
}

\section{(2) OpenEdition}

\section{Journals}

\section{Édition électronique}

URL : https://journals.openedition.org/ahrf/10683

DOI : 10.4000/ahrf.10683

ISSN : $1952-403 X$

Éditeur :

Armand Colin, Société des études robespierristes

Édition imprimée

Date de publication : 1 septembre 2009

Pagination : 212-215

ISBN : 978-2-200-92559-8

ISSN : 0003-4436

\section{Référence électronique}

Cyril Triolaire, "Natalie Petiteau, Les Français et l'Empire (1799-1815) ", Annales historiques de la Révolution française [En ligne], 357 | juillet-septembre 2009, mis en ligne le 09 décembre 2009, consulté le 24 avril 2022. URL : http://journals.openedition.org/ahrf/10683 ; DOI : https://doi.org/ 10.4000/ahrf.10683

Ce document a été généré automatiquement le 24 avril 2022.

Tous droits réservés 


\title{
Natalie Petiteau, Les Français et l'Empire (1799-1815)
}

\author{
Cyril Triolaire
}

\section{RÉFÉRENCE}

Natalie Petiteau, Les Français et l'Empire (1799-1815), Paris, La Boutique de l'Histoire Éditions universitaires d'Avignon, 2008, 278 p., ISBN 978-2910828462, $25 €$

1 Quel est le principal point commun entre Claude-Antoine Bellod, menuisier de l'Ain, Letain, sabotier de Sens, le dit Léon, jeune tailleur parisien, Gardin Dubois Dulié, ancien émigré de la Loire-Inférieure, et le curé de Saint-Arnoult en Yvelines ? Celui d'avoir vécu sous Napoléon. Quel est le grand mérite de Natalie Petiteau ? D’avoir prêté toute son attention à ces «Français d'en bas". À revers d'une historiographie classique faisant souvent la part belle aux recherches institutionnelles, diplomatiques ou militaires, Natalie Petiteau décide à travers son nouvel opus de scruter la vie de la majorité des Français entre Consulat et Empire et de saisir leurs réactions à l'autorité napoléonienne, en faisant d'ailleurs davantage la part belle aux formes de contestation qu'à celles d'adhésion. Réussissant là où Jean Tulard avait échoué dans sa Province au temps de Napoléon (éditions SPM, 2003) et emboîtant parfaitement le pas du pertinent et plaisant Quand les enfants parlaient de gloire de Jean-Paul Bertaud (Aubier, 2006), l'historienne choisit de scruter cette opinion publique érigée au rang d'acteur politique en Révolution, d'apprécier «l'état des esprits» afin de saisir le plus justement les représentations de Napoléon et de son régime dans l'espace public. Jamais dupe de cette impossibilité à tout saisir, les silences volontairement gardés sur nombre d'événements par une administration soucieuse de ne pas s'attirer les foudres gouvernementales et de témoigner de sa capacité à tenir ses concitoyens l'en empêchant, l'auteur s'affère à relever les mots et les gestes des Français durant près de quinze ans. Correspondances préfectorales, archives judiciaires et sources policières (parmi lesquelles les bulletins - souvent incomplets - publiés successivement par Grassion, d'Hauterive et Gotteri sont abondamment sollicités) lui fournissent, depuis 
les dépôts parisiens et régionaux (ceux du Var et du Vaucluse, bien connus de l'auteur sont davantage utilisés), matière à mener une " histoire sociale du politique telle que les actions du régime la donnent à voir ». En multipliant les angles de vue, en écoutant aussi bien les ministres que les généraux de la grande armée, les notables que les anonymes, Natalie Petiteau essaye de cerner et d'analyser au mieux les attitudes des Français face à l'Empire et à Napoléon. S'appuyant sur une riche bibliographie à jour des productions les plus neuves - à l'exception de l'épisode des Cent Jours où Henry Houssaye devient sa référence trop souvent exclusive-, l'auteur privilégie une approche résolument chronologico-thématique "pour souligner les inflexions du temps court si dense ", en sept temps.

2 Ses premières pages sont consacrées à l'accueil du Consulat et rappellent combien, à la suite d'une Révolution qui a su cultiver le culte des grands hommes, le recours au "héros» Bonaparte s'impose de fait. En remédiant à l'instabilité politique du Directoire, en portant les espoirs de paix intérieure et extérieure et en consolidant l'héritage révolutionnaire, le premier consul sauve alors la République autant qu'il répond à une véritable attente collective. La relecture des événements proposée dans ce chapitre montre pourtant combien l'avènement du Consulat, du coup de force militaire et parlementaire de Brumaire au plébiscite constitutionnel de l'an VIII, est loin de faire l'unanimité. Les heurts enregistrés dans certains départements, la méfiance des milieux marchands et le scepticisme manifeste d'un certain nombre - reflet de comportements individuels aussi bien que communautaires, à la campagne notamment -, rappellent combien l'acceptation du nouveau régime fut relativement animée. Tandis que l'héroïsation de Bonaparte et la personnification du pouvoir se poursuivent et les marques d'attachement au premier consul se multiplient, l'espace public résonne d'oppositions vivaces. Si les accords de paix signés à Lunéville et surtout à Amiens convainquent une large frange de l'opinion publique, ce sont bien une gouvernance et une surveillance renforcées des esprits qui doivent permettre au héros d'asseoir définitivement son autorité et de soutenir son système politique.

3 L'entreprise de séduction et d'enrégimentement des consciences est lancée à grande échelle et emprunte diverses voies que l'auteur s'efforce de suivre. Dans un espace public où les libertés sont de plus en plus restreintes et où l'histoire est sans cesse réécrite, tous les discours doivent promouvoir le régime, justifier la confiscation du pouvoir entre les mains d'un seul et rendre incontestable son exercice. Temps privilégiés de la mise en scène du pouvoir, les fêtes officielles promeuvent autant le nouvel ordre social et militaire national qu'elles consacrent désormais le culte du seul Napoléon. Symboles aux yeux de l'auteur de l'alliance renouvelée du trône et de l'autel, les cérémonies publiques impériales réactivent également celle du sabre et du bénitier, pour paraphraser Jean-Paul Bertaud, et deviennent les temps forts d'une dévotion spontanée devenue obligatoire. L'orientation de l'opinion passe incontestablement alors aussi par le strict contrôle des écrits et des arts : la police devient le « ministère de l'opinion ». Se faisant parfaitement l'écho des travaux neufs actuellement menés sur ce thème-ci, Natalie Petiteau se contente d'évoquer le muselage de la presse, le contrôle des arts picturaux, la censure théâtrale et l'engagement de plumes zélées sans chercher plus en avant parmi les choix et les attitudes des gazetiers, des petits comédiens et magistrats des départements les marques inédites de soutien ou d'opposition au régime. Malgré des voix dissonantes - repérables à travers les chansons, ignorées ici -, une glorification systématique de Napoléon est bien engagée ; mais s'il est bien loué tel 
un « héros » ou un "grand homme », jamais pourtant les Français ne reconnaissent en lui ce saint qu'il a voulu incarner (p.95). Surtout, tous n'adhérent pas à la propagande gouvernementale et aux propos de circonstance. Les deux chapitres suivants révèlent d'ailleurs parfaitement la persistance de réseaux d'opposants structurés et l'existence de refus anonymes.

4 S'inscrivant dans une culture de l'insurrection, de véritables oppositions persistent sous l'Empire. Sans évidemment omettre les plus fameux complot - Cadoudal-Pichegru et conspiration Malet - l'historienne prête une attention toute particulière aux actions individuelles et collectives de royalistes hostiles à l'« usurpateur " et de républicains stigmatisés, décimés et parfois singulièrement actifs - à l'inverse d'idéologues déçus privilégiant une opposition législative ou silencieuse. Mais c'est en observant les soldats que l'auteur renouvelle le mieux l'historiographie traditionnelle. Le vif ressentiment suscité par la réorganisation militaire consulaire et les différences de traitement nourrissent le mécontentement de certains officiers, au point qu'ils se structurent efficacement. Entre indocilité et activisme, l'opposition la plus originale mise à jour est évidemment celle des anonymes, de ces Français d'en bas jusqu'alors largement oubliés par les spécialistes de la période. Notables récalcitrants, sous-préfets négligents, magistrats municipaux rétifs et curés réfractaires à la dévotion napoléonienne ou instituteurs opposés au gouvernement, ils semblent nombreux à miner le régime de l'intérieur, à contester l'ordre administratif et social et à multiplier les actes séditieux et inciviques. Si l'auteur néglige parmi les formes d'opposition l'impact de la résistance ecclésiastique à la mise en circulation et à l'utilisation du nouveau catéchisme impérial, elle révèle en revanche parfaitement, en se plaçant à l'échelon départemental, les imperfections multiples de l'encadrement politico-administratif sur lequel le pouvoir central croit pouvoir indubitablement compter. Certains soutiens apparaissent néanmoins indéfectibles et sincères, et ce, même si ces Français éduqués en Révolution semblent redevenus de simples sujets, heureux pour certains de renouer avec la geste d'une monarchie très chrétienne. Très sensibles aux espoirs de paix portés par leur chef, les Français reconnaissent en Napoléon cet « empereur de guerre » incarnant la gloire de toute la nation. Notables dévoués à l'État et influents, simples quidams maniant difficilement la plume, desservants obéissants ou évêques dépositaires d'une vraie théologie de la guerre, les thuriféraires francs ne manquent pas, l'adhésion de quelques uns étant même facilitée, au lendemain d'une décennie qui a bouleversé leurs repères, par la restauration d'une grille d'interprétation politique familière et signifiante (p.180). La reconnaissance et l'admiration dont jouit le prince, fondateur d'une $I^{\text {e }}$ dynastie à même de pérenniser le nouvel ordre national, résistent bientôt pourtant difficilement au schisme avec Rome, aux déconvenues militaires et à la crise économique.

5 En envisageant la chronologie du déclin de l'Empire à partir de 1807 à travers les yeux des Français, l'auteur montre justement comment la dure réalité de la guerre et les difficultés quotidiennes éprouvées pour se nourrir et travailler écornent durablement l'image de Napoléon, au point d'être rendu responsable des principaux maux du pays. La pression policière n'étouffe et ne jugule finalement qu'un temps les contestations, le régime ne survivant pas, malgré un évident ultime sursaut patriotique, au désastre russe et à l'invasion. La première Restauration agit dès lors tel un précieux révélateur. Face aux girouettes chères à Pierre Serna, un nombre certain de Français n'hésitent pas en effet à afficher leur fidélité, leur royalisme ou bien leur " napoléonisme » (p. 223). Si la débâcle militaire française suffit à réactiver ici des mouvements contre- 
révolutionnaires et à entretenir là l'espoir d'une réhabilitation des anciens rois, l'idée d'un maintien des Napoléonides sur le trône est généralement partagée et ce, malgré la montée des mécontentements. D'ailleurs, la restauration des Bourbons, célébrée avec un enthousiasme débordant au cœur de terres bleues toujours restées fidèles ou, sans doute plus fréquemment, de circonstance dans de multiples cités, l'auteur rappelle l'indifférence qui l'accompagne parfois dans certains départements. La passion suscitée par l'empereur déchu est pourtant à la hauteur du tremblement de terre politique vécu. Il ne laisse alors indifférent ni ses plus farouches opposants qui s'empressent de ternir son portrait, ni de ses partisans - des officiers aux simples civils - qui se risquent véritablement à afficher leur sentiment le plus sincère en proférant des cris désormais séditieux. Les déceptions rapides de tout ordre - symbolique, cérémonielle, militaire, fiscale et sociale à bien des égards - empêchent aux Bourbons de s'imposer et motivent le ralliement d'un nombre certain de Français à Napoléon au moment des Cent Jours. Natalie Petiteau met alors en lumière la distorsion existant entre un pays majoritairement - ? - soucieux de renouer avec l'héritage révolutionnaire consolidé par l'ex-prince et le vif désir de celui-ci de restaurer et son autorité absolue, et l'apparat seyant à sa cour. Au cœur d'un espace public redevenu relativement « libre » par défaut, le vote sur l'Acte additionnel aux constitutions de l'Empire, le rassemblement du Champ de Mai puis la seconde abdication témoignent à bien des égards alors de la fragilité du sentiment napoléonien des uns et des autres, et même des bonapartistes de la première heure.

6 La France consulaire et impériale expérimente une nouvelle, une troisième voie politique, entre républicanisme et monarchie bourbonienne, et reconnaît en Napoléon ce chef charismatique en qui "peuvent s'incarner tous les espoirs de rénovation sociale» (p. 255). Si une grande majorité de Français semble bien avoir accepté adhéré - au régime, parfois même très sincèrement, le temps des défaites et de la morosité économique favorise les oppositions. Car dans cet espace public français policé, surveillé et muselé, les contestations sont multiples, et ce, même si elles restent impossibles à toutes recenser, tant les administrateurs locaux les voient d'un mauvais œil et préfèrent souvent les taire. Une mise en perspective plus systématique des bulletins de la police transmis quotidiennement à l'empereur avec des enquêtes de terrain ciblées, à l'échelon départemental, aurait d'ailleurs sans doute permis de se rapprocher plus justement encore du véritable "niveau de résistance " au pouvoir napoléonien des régions. En menant une enquête exclusivement qualitative - au nom d'une impossible exhaustivité - et en prenant résolument le parti de ne pas quantifier, l'historienne s'empêche d'apprécier justement l'importance de cette France séditieuse. $\mathrm{Si}$, comme elle l'indique parfaitement et à juste titre, les situations locales sont complexes et le partage entre une France impériale et l'autre royaliste sans doute simpliste, l'absence totale de cartes, au niveau national et surtout départemental, ne permet ni de s'ôter cette dernière idée de l'esprit ni même d'« affiner » régionalement notre perception du «sentiment napoléonien ». L'ouvrage de Natalie Petiteau ne s'en impose pas moins déjà comme une référence incontournable de l'étude des Français, de l'opinion et de sa place dans l'espace public, entre 1799 et 1815 , en relisant en profondeur le mythe d'une France impériale admirative et aux ordres, et ouvrant, comme elle a déjà su le faire auparavant, des voies nouvelles pour l'histoire de l'Empire. 